\title{
ACQUISITION OF ARTILLERY PROJECTILE DATA DURING IN-BORE TRAVEL USING RF TELEMETRY
}

\author{
DAVID N. EVERSWICK \\ LEON H. GLASS \\ ROBERT J. HARRINGTON \\ TECHNICAL SUPPORT DIRECTORATE \\ U. S. ARMY ARMAMENT RESEARCH AND DEVELOPMENT COMMAND \\ DOVER, NEW JERSEY 07801
}

\begin{abstract}
The U. S. Army Armament Research and Development Command (ARRADCOM), has had a need for a number of artillery projectile telemetry systems to obtain in-bore and inflight data. This paper provides a brief description of some of these systems along with the non-destructive testing techniques that have been utilized for verifying the gun hardness of telemetry components and systems. Examples of in-bore environmental data obtained during actual firings are presented and discussed.
\end{abstract}

\section{INTRODUCTION}

The advent of highly sophisticated artillery projectiles, such as the family of fire and forget guided projectiles and sensing munitions incorporating a variety of on-board sophisticated electronics (such as multiple on-board micro-computers and special purpose sub-systems for performing guidance, control and fuzing functions), specialized metallurgy, and packaging techniques in the system design, has resulted in a growing need for telemetry support to monitor the in-bore and in-flight performance of the projectile and characterize the environment experienced by it. In the past, the performance of many artillery projectiles was evaluated statistically by firing a large number of rounds without telemetry and by monitoring the dud rate to estimate satisfactory performance by statistical inference. This approach was utilized on most high-explosive ballistic projectiles because of their low unit cost compared to the high cost of telemetry and because of their relative simplicity. RF telemetry was utilized sparingly, mostly for in-flight performance on nuclear projectile programs.

Many projectile anomalies have been proven or surmised to have occurred during the inbore environment where typical acceleration forces can reach levels of 17,000 g's with angular accelerations of more than 334,000 radians per second squared for a $155 \mathrm{~mm}$ 
projectile. For this reason, there has been increased interest in obtaining in-bore telemetry data on projectiles currently under development and on older programs where in-bore telemetry was not obtained during development if investigations become necessary. Within the past few years, the state-of-the-art of telemetry components has progressed to the point where high quality, reliable, high frequency response in-bore data acquisition is achieveable.

This paper reviews two hardwire techniques that were utilized for evaluating the gun hardness of critical telemetry components followed by a description of three RF telemetry systems utilized to obtain in-bore data. Gun hardness qualification testing using the ARRADCOM rail and air guns will also be presented. Finally, typical data obtained from test firings will be presented.

\section{HARDWIRE TELEMETRY}

Hardwire telemetry is a relatively inexpensive technique for performing gun hardness testing of components during the in-bore environment. Two collector cup designs have been used to date. The front of the initial collector cup configuration is shown in Figure 1. Long insulated wires are connected to the items under test and these items are then potted into the lower portion of the collector cup. The cup is screwed into the standard fuze well of a projectile (Figure 2). The insulated wires are then run out of the gun tube to a recorder where the in-bore performance data of the item under test is recorded.

Using this technique, a series of tests were conducted on two brands of nicad batteries to determine which would be best for use as in-bore telemetry power supplies. Samples of button and cylindrical cells from both manufacturers were tested with both positive and negative terminals forward (direction of flight). Test results indicated that the cylindrical cells from both manufacturers occasionally developed permanent internal cell shorts as a result of the in-bore environment. Also, both button cells open momentarily during the inbore environment if the positive terminals are facing forward. A preferred battery and its orientation were selected based on these results.

The major problem with this collector cup technique, is that, on high charge zone firings, the wires running out of the gun barrel break in the first 10 to 12 inches of travel prior to achieving peak in-bore acceleration (approximately 80 percent of peak) before complete, data can be obtained.

The modified collector cup shown in Figure 3 overcomes this problem. This cup is much smaller than the initial collector cup design (less than three inches in diameter). It consists of an upper metal cup separated from the lower metal base by an electrical insulator. The assembly screws into the projectile's fuze well. A single long non-insulated wire is 
connected to the upper cup, extended out the gun tube and supported on the longitudinal axis of the gun tube so that it does not come in contact with the tube. This lead is connected to the signal input of a tape recorder. The output of the item under test located in the base of cup is connected to the metal cup and it's ground to the metal base. When the projectile is fired, the cup makes nearly continuous contact with the wire during inbore travel, since the cup is essentially fired into the wire. If there is a momentary break in this wire at the collector cup, there is an almost immediate remake because of the cup's forward velocity into the wire. The ground of the metal base is fed through the projectile to the gun tube (through the projectile's rotating band interface to the gun tube rifling) and to the tape recorder.

To facilitate environmental testing of powered-up instrumentation amplifiers with the cup and to eliminate the necessity for batteries, capacitors were charged with an exterior insulated wire (note lead in Figure 3). Once this projectile is fired, this wire breaks, but there is sufficient charge stored in the capacitor to power the components under test for the duration of the in-bore environment, usually about 20 milliseconds.

One of the drawbacks with this approach is that it is only a single channel system. Also, the signal-to-noise ratio of the data obtained has been marginal because of the continuous break and make action of the cup to the wire.

\section{RF TELEMETRY}

RF telemetry has been used to obtain complete in-bore and/or in-flight telemetry data on a number of projectile development programs at ARRADCOM. Although this technique is usually more expensive than the hardwire approach, excellent quality in-bore data has been consistently obtained.

The family of telemeters described below had their origin in the Model ARRT-48 Telemeter for the Cannon-Launched Beam Rider Projectile (CLBRP) a $105 \mathrm{~mm}$ anti-tank laser-guided projectile in exploratory development at ARRADCOM in the mid 1970's. The measurement requirements dictated that data was required within a few milliseconds after muzzle exit. Most projectile RF transmitters until that time were not crystalcontrolled. This was acceptable for obtaining data during free-flight if the expected data occurred late enough in the trajectory to permit re-tuning of receivers to follow the drift in carrier frequency caused by the affect of the in-bore environment on the transmitter components. The only crystal-controlled transmitter available was a 200 milliwatt $\mathrm{L}$ or S-band unit that had been qualified to survive a $155 \mathrm{~mm}$ in-bore environment, but the maximum charge zone for a $105 \mathrm{~mm}$ projectile causes a set-back acceleration of about $27,000 \mathrm{~g}$ 's, significantly higher than the $17,000 \mathrm{~g}$ 's experienced by a $155 \mathrm{~mm}$ projectile. The transmitter was redesigned to further ruggedize it to the $105 \mathrm{~mm}$ environment. It was 
then tested in the ARRADCOM air gun and qualified to operate through accelerations equivalent to a howitzer environment in excess of 50,000 g's set-back. The resulting telemetry system is described below under the ARRT-62 Telemeter.

Following is a brief description of three RF telemetry systems used for acquisition of inbore data.

\section{Model ARRT-52 Telemeter for the XM785 155 mm Projectile}

Figure 4 is the ARRT-52 telemeter that was developed in 1979 to satisfy the requirement for strain data from the interior wall of a $155 \mathrm{~mm}$ projectile during in-bore travel. The telemeter is 4-3/8 inches in diameter and five inches long and has been qualified to levels in excess of 16,000 g's in the ARRADCOM air and rail guns. Excellent quality in-bore data has been obtained with this telemeter and examples of data are presented later in this paper. The telemeter utilizes a tapered printed circuit wrap-around antenna that is assembled into the ogive section of the projectile casing. This antenna, designed and manufactured by Ball Aerospace Corporation, excites the gun tube as a waveguide and provides exceptionally good signal strength at the telemetry receiving station. The antenna also provides good in-flight antenna pattern coverage. The S-band 200 milliwatt crystalcontrolled transmitter described above is utilized. S-band was selected to insure that the telemeter would be operating well above the waveguide cut-off frequency of a $155 \mathrm{~mm}$ gun tube. It was felt to be necessary to have the transmitter crystal controlled to minimize any incidental FM of the transmitter caused by in-bore acceleration forces or the position of the projectile within the waveguide (gun tube). The telemeter includes a multiplexer module that contains 13 VCO's as follows: one constant bandwidth IRIG "A" channel, 10 constant bandwidth IRIG "B" channels and two proportional bandwidth (IRIG) channels. This module is interchangeable with a $300 \mathrm{kbit} / \mathrm{second}$ PCM encoder module that has six bit words, 16 words per frame and a $12 \mathrm{kbit}$ shift register. The intent of the PCM module was to delay in-bore data transmissions by 40 milliseconds or until the projectile exits the gun tube and is clear of the ionized cloud at muzzle exit, at which time data transmission optimized. However, it was found that this feature was not needed even with severely worn gun tubes where there was concern that excessive ionized gas blow-by might cause an RF blackout. The telemeter contains eleven low-level signal conditioning bridge circuits with precision bridge completion resistors, RFI and data filters, instrumentation amplifiers, limiters, and a precise bridge excitation voltage source. Two battery packs are contained within the telemeter, one for powering the telemeter and one for providing excitation to the bridge circuits. In addition, the telemeter contains an accelerometer to measure longitudinal acceleration. 


\section{Model ARRT-62 Telemeter for the M483A1 155 mm Projectile}

Shown in Figure 5 is a telemeter developed to acquire in-bore strain data on the M483A1 $155 \mathrm{~mm}$ Projectile. The telemeter consists of two modules, a basic module consisting of the ARRT-48 CLBRP Telemeter described previously and a signal conditioning module developed in 1980 to adapt this telemeter to the data requirements of the M483A1 Projectile. The basic module, shown on the left of Figure 5, measures only 3-1/4 inches in diameter and 4.5 inches in length. It contains a crystal-controlled 200 milliwatt S-band transmitter, a 48-channel PAM commutator, six VCO data channels, and nicad battery pack with sufficient capacity for almost one hour of operation. It is completely hardpotted, but can be modified or repaired due to interior tapered walls and a plunger assembly that is used to remove the electronics and battery sections. The signal conditioning module, which is 3-1/4 inches in diameter and 4-3/4 inches long, contains eleven low level signal conditioning circuits and a bridge excitation power supply regulation circuit. Electrically, the signal conditioning circuits are very similar to those used on the ARRT-52 telemeter except that each signal conditioning channel and the bridge excitation regulator are packaged on individual printed circuit boards and use discrete components instead of hybrid circuits. This provides a very flexible design that can be readily adapted to changing instrumentation requirements. The signal conditioning module plugs into the basic telemetry module using ITT Cannon MDM metal shell connectors. A printed circuit wrap-around antenna designed and manufactured by Ball Aerospace Corporation is fitted to the outside surface of a special ogive section of the projectile that was developed to house the telemetry system. Excellent in-bore data has been obtained with this telemeter.

\section{Model ARRT-46 Telemeter for the Ballistic Rail Gun}

Shown in Figure 6 is a modular general-purpose projectile telemeter that was developed in early 1981 for instrumenting the ARRADCON ballistic rail gun. This system is very flexible and can he easily modified because of its modular design. The telemeter consists of a battery module (far right in Figure 6), a VCO and transmitter module (center of Figure 6) containing 13 VCO's, and a signal conditioning module (far left in Figure 6).

The overall size of this telemeter (see Figure 7) is 3-1/4 inches in diameter and 9-1/4 inches long. The three modules plug into each other using ITT Cannon MDM connectors. The signal conditioning module is the same as used on the M483A1 telemeter. The VCO's, transmitter, and battery pack components are the same as previously employed on the XM785 and M483A1 telemeters. To date, this telemeter has been utilized to support rail gun testing at ARRADCOM. Excellent quality in-bore and in-rail data has been obtained. Plans are currently underway to use this telemeter design with some signal conditioning modifications to support additional in-bore and in-flight XM785 testing and to 
acquire longitudinal acceleration data in-bore through exit shock on a new eight-inch guided projectile in advanced development. Due to the expected high frequency content of the axial exit shock, up to nine constant bandwidth proposed IRIG 'E' channel VCO's will be used in each telemeter.

A new modular telemetry system is presently under development that is similar to this unit as far as mechanical packaging, but will be capable of handling greater instrumentation requirements.

\section{QUALIFICATION TESTING}

Before any telemeter is certified for use, it must undergo a series of qualification tests that include air and/or rail gun testing. If the telemeter is to be used to obtain in-bore data, it is tested in its "on" or active state during gun qualification testing. The output is recorded and each telemeter channel is checked to insure proper operation. If it is to be used to obtain in-flight data only, the telemeter is checked before and after being subjected to the gun environment to insure that the telemeter survived and works after exposure to the environment. This type of passive testing is performed where possible to minimize qualification test costs associated with providing real time telemetry ground station coverage.

\section{Air Gun}

Figures 8 and 9 show the air gun soft recovery facility at ARRADCOM. This facility presently has five-inch and two-inch smooth bore air guns. A $155 \mathrm{~mm}$ air gun with rifling is in the process of being readied for use. To obtain active, air gun telemetry data, a telemeter is installed into a five-inch air gun cannister along with the item under test. A scimitar antenna is mounted on the forward surface of the cannister with a receiving antenna mounted on the bulkhead at the capture end of, and extending into, the air gun chamber. Since the air gun is less expensive to use than the rail gun, it is a desirable method of performing initial system and component testing. It has been found that, for testing telemetry components, the air gun levels must he carefully controlled to avoid an overtest. The air gun is a diaphragm-fracture device that has a very rapid acceleration rise time (in low microseconds vs low milliseconds for an actual gun firing) that generates excessive high frequency shock components not normally found in actual gun firings except at muzzle exit, but at lower amplitudes. These high frequency components can excite the small telemetry electronic parts and devices that have high natural resonant frequencies and cause them to fail. By analyzing the item to be tested and judiciously selecting the proper test levels, the air gun has proven to be a valuable tool for checking the gun hardness of electronic sub-assemblies and devices. 
A test effort was conducted with the ARRADCOM air gun to qualify the crystal-controlled transmitter discussed previously. The transmitter was fired passively many times in the air gun while developing a crystal packaging design that would protect the crystal from failing at air gun acceleration levels in excess of $38,000 \mathrm{~g}$ 's, which is equivalent to actual gun firings in excess of 50,000 g's.

\section{Rail Gun}

Figures 10 and 11 show the ballistic rail gun soft recovery facility at ARRADCOM. A water scoop is connected to the front of an M483A1 projectile casing and fired from the $155 \mathrm{~mm}$ gun into an array of four rails designed to capture the projectile. At the bottom of the rail is a water trough which the scoop enters and thus the projectile is slowed to a stop within 100 feet.

To obtain in-bore or in-rail telemetry data, the projectile is outfitted with any of the previously discussed telemetry systems. A water scoop (Figure 12) with an antenna mounted in its base is assembled to the projectile (Figure 13). This antenna provides excellent in-bore data. But, when this projectile enters the rails, the water shorts out this antenna with the attendant loss of in-rail data. To overcome this, a wrap-around antenna is mounted on the surface of the projectile body to provide transmission of the in-rail data.

Newly developed telemetry systems are qualified in the rail gun prior to their use to insure ' $\mathrm{g}$ ' hardness of design. Also, there is sufficient room in the M483A1 projectile casing to carry fairly large projectile component specimens instrumented with the telemeter.

The rail gun is somewhat of an over-test compared to an actual firing because of the in-rail balloting and set-foward forces encountered during slow-down of the projectile in the water break.

At present, rail gun qualification test costs are more expensive than that of the air gun.

It has been observed that, once a telemetry system has been gun-hardened, there has been only minor fatiguing effects observed from repeated gun firings. Some telemetry systems have been fired more than a dozen times in the rail gun without any noticeable degradation in system performance.

\section{IN-BORE DATA}

Following is a brief discussion of some typical in-bore data obtained using the ARRT-52 telemeter in XM785 projectile gun tests. The measurement requirements for these tests were to monitor projectile strain levels on the inner wall of the shell casing during in-bore 
travel. The inner wall of the projectile was instrumented with a number of Vishay Intertechnology, Inc. strain gauges. Eight strain gauges were simultaneously telemetered along with two "strain type" reference channels, one axial acceleration channel and two telemetry battery monitor channels. The projectiles were designed for parachute recovery to permit postmortem analysis of the projectile casing and re-use of the telemetry system. The data presented in this section is raw telemetry data and has not been filtered or processed in any way.

Three test firings took place at Yuma Proving Grounds in June 1980. All firings were conducted at a gun quadrant of elevation of approximately 90 degrees for proper parachute recovery system operation. A new $155 \mathrm{~mm}$ M199 gun tube was used for all firings. Two rounds were fired usingM203 propellant charges and one round was fired with an M3A1 propellant charge. All telemeters functioned properly with a very good signal to noise ratio on all channels. A Kulite piezoresistive accelerometer was used. Figure 14 is a data trace of longitudinal acceleration vs time. Please note that there is a linear portion in the initial rise of the acceleration trace. This is characteristic of high charge zone firings. The acceleration peaks at approximately 13,000 g's and decays until muzzle exit. At exit, an exponentially decaying high frequency sinusoid of approximately $13 \mathrm{kHz}$ is observed for about two milliseconds. This high frequency ringing is a result of the gun in-bore forces suddenly being removed from the projectile at muzzle exit. Also, one can observe during the initial portion of free-flight that there has been a shift in the accelerometer base line from that observed prior to firing. This is probably the result of the accelerometer taking a permanent set as a result of the in-bore environment and/or accelerometer cross-axis coupling due to spin. It is highly desireable to obtain some initial free-flight data on all inbore transducers, even if one is only interested in the in-bore data, so that the operation of the transducers can be observed after the high stress environment to see if there was any substantial degradation caused by the in-bore environment. From this, an estimate of the in-bore data quality can be made.

Figure 15 is the first integration of acceleration, or velocity. Exit velocity is observed to be very close to the calculated value of 2,735 feet per second. The in-flight velocity profile is not valid due to the accelerometer offset. Figure 16 is the second integration of acceleration, or displacement. Displacement to muzzle exit corresponds, closely to the design length of the M199 gun tube. Again, the in-flight displacement is not valid due to the accelerometer offset.

Figure 17 is a typical strain measurement. It can be observed that the maximum strain of just under 10,000 microinches per inch occurs near maximum acceleration. Also, time slight base line shift from zero that can be observed prior to firing is actually strain in the wall of the projectile after ramming into the forcing cone of the gun tube. 
Figure 18 is a telemetry reference channel. This channel is identical to the other strain channels, except that a fixed 350-ohm resistor is connected to the bridge input instead of a 350 -ohm strain gauge. This channel should be stable at all times. Any variation in this channel is telemetry-induced noise. Only a small amount of telemetry noise (approximately five percent) was observed at muzzle exit.

\section{CONCLUSION}

Proven projectile telemetry systems have been presented that provided excellent quality inbore data through muzzle exit. Qualification testing techniques have also been presented that insure very high telemetry reliability. At this point, high "g" transducers appear to be the weak link in obtaining in-bore environmental data.

\section{ACKNOWLEDGEMENT}

The authors wish to acknowledge the very valuable contribution of Microcom Corporation as manufacturer of much of the telemetry hardware described in this report. We also wish to acknowledge the typing and editing efforts of Ms. Sandi Mantook of ARRADCOM.

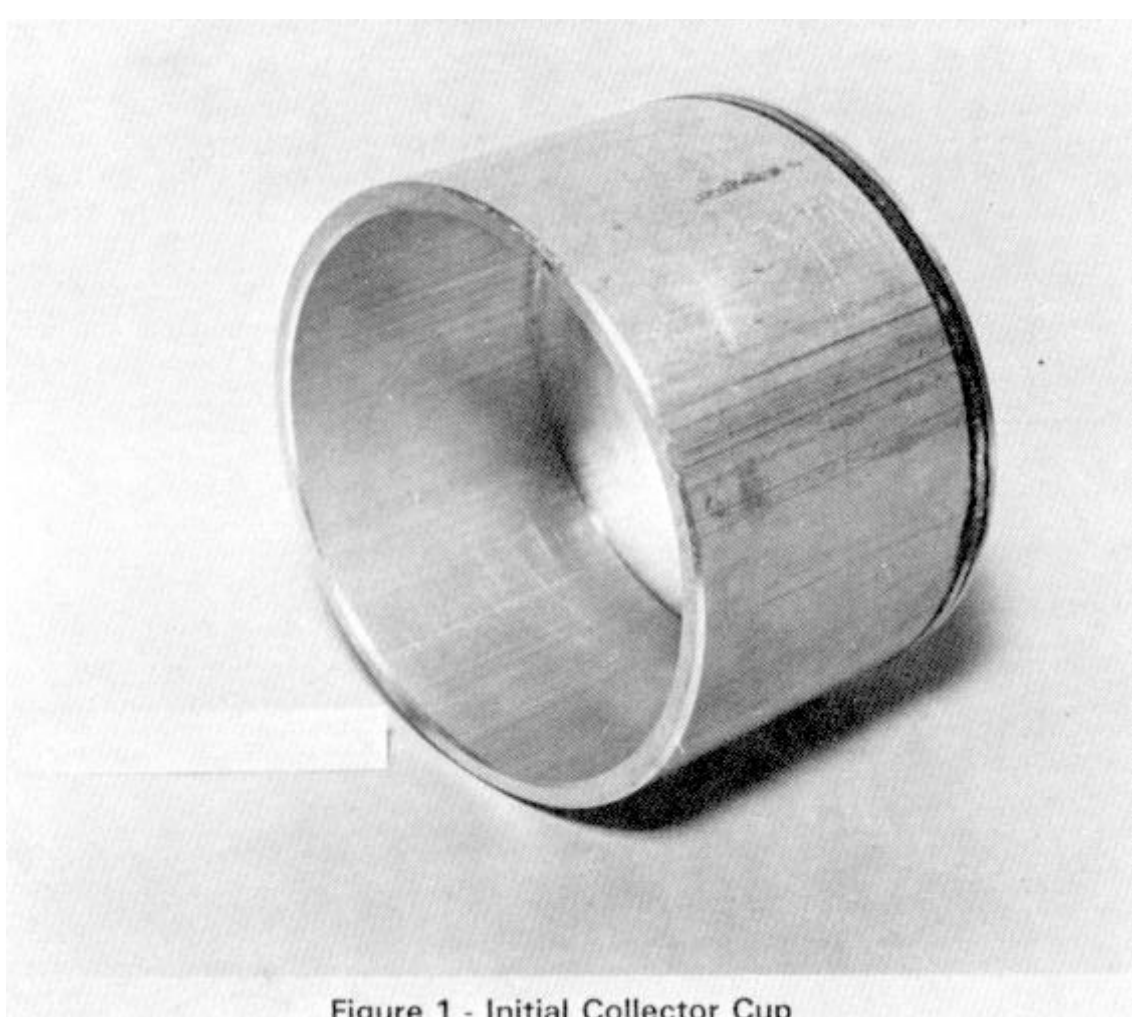

Figure 1 - Initial Collector Cup 


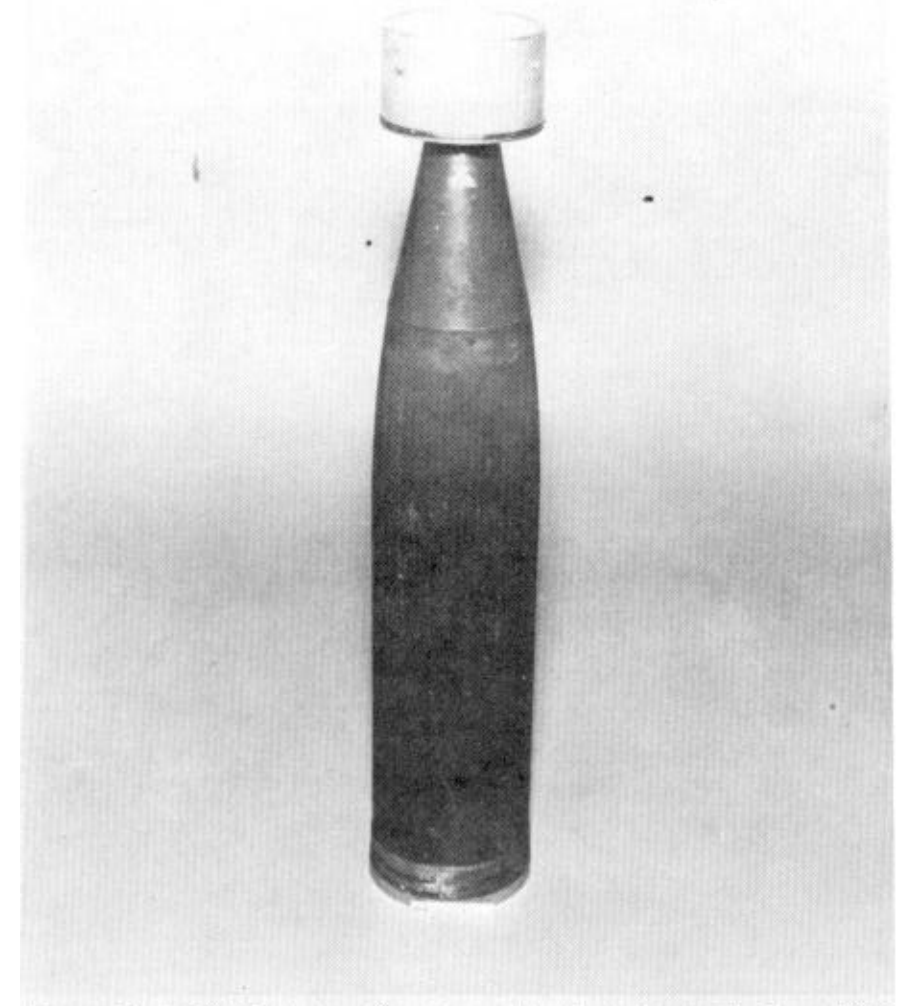

Figure 2 - Initial Collector Cup Assembled into Projectile Fuze Well

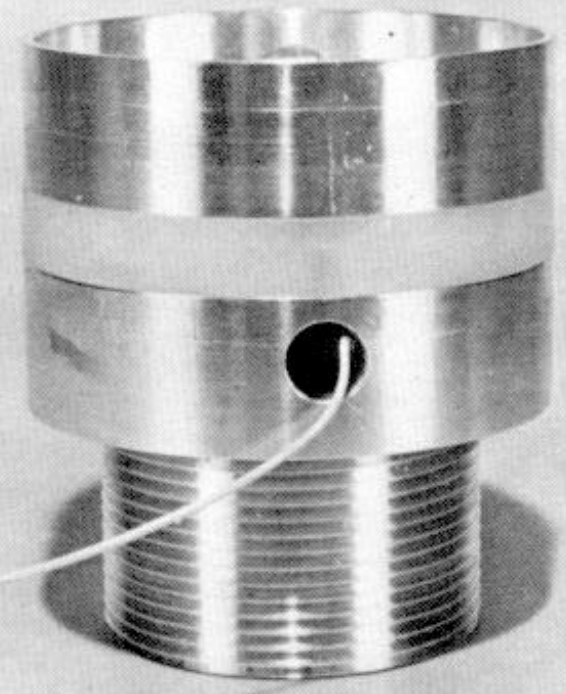

Figure 3 - Modified Collector Cup 


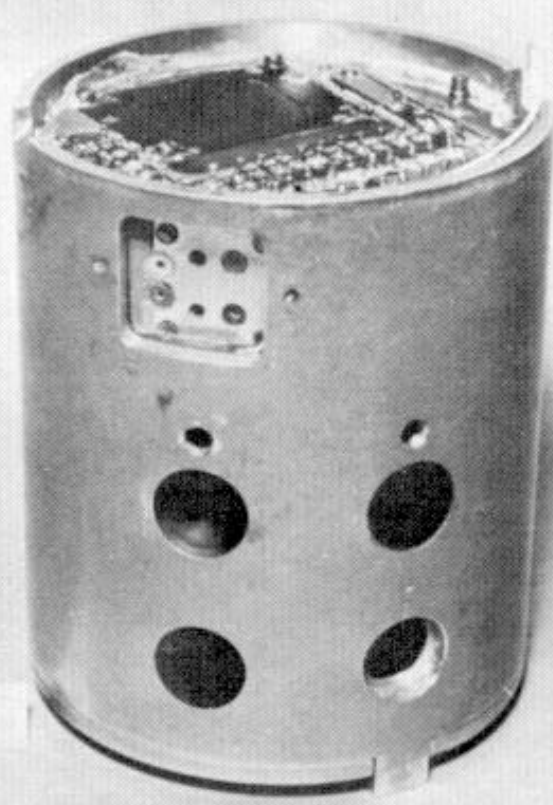

Figure 4 - ARRT-52 Telemeter

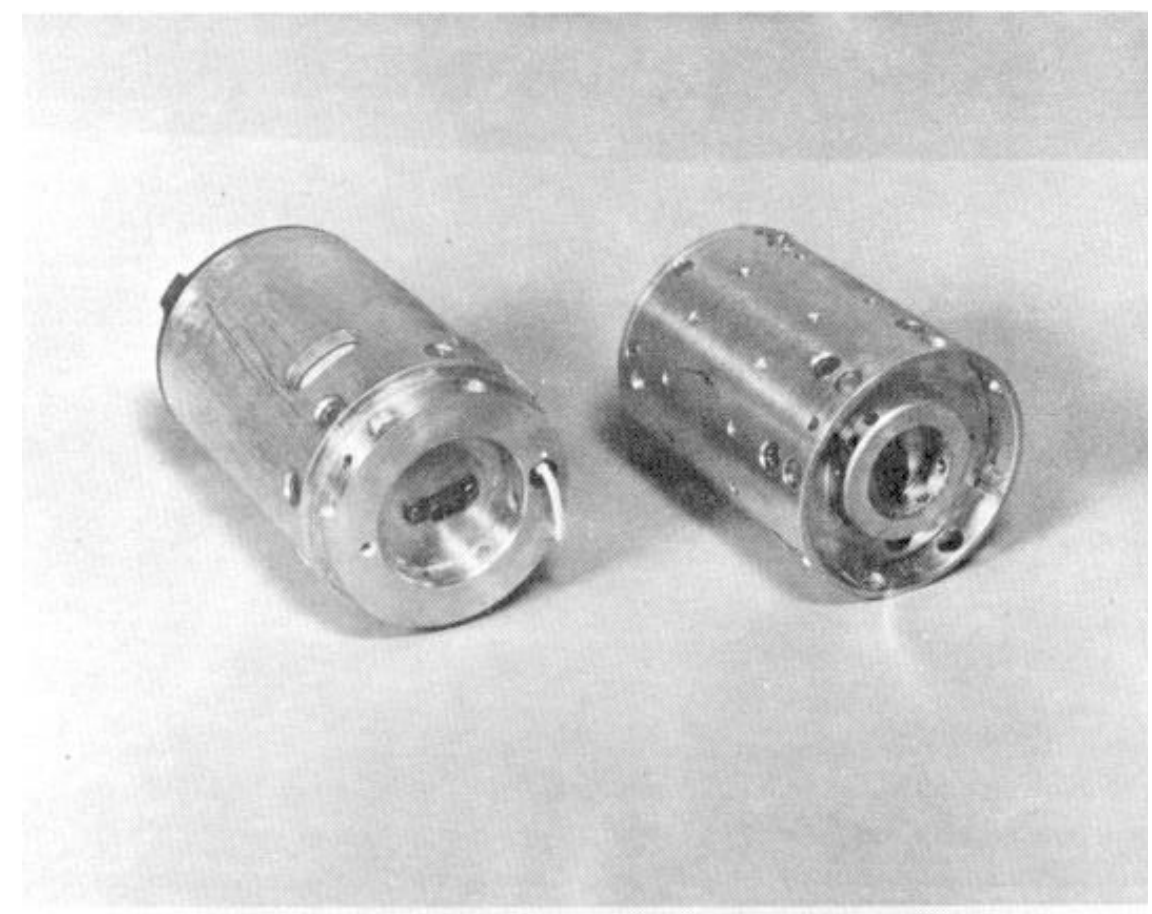

Figure 5 - ARRT-62 Telemeter 


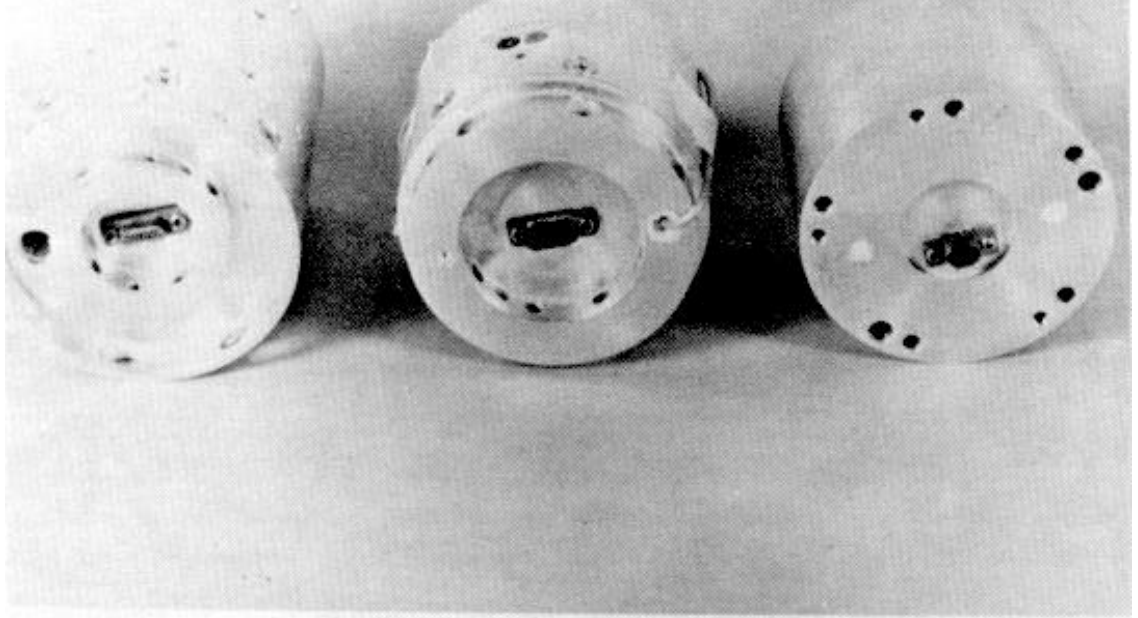

Figure 6 - ARRT-46 Telemeter

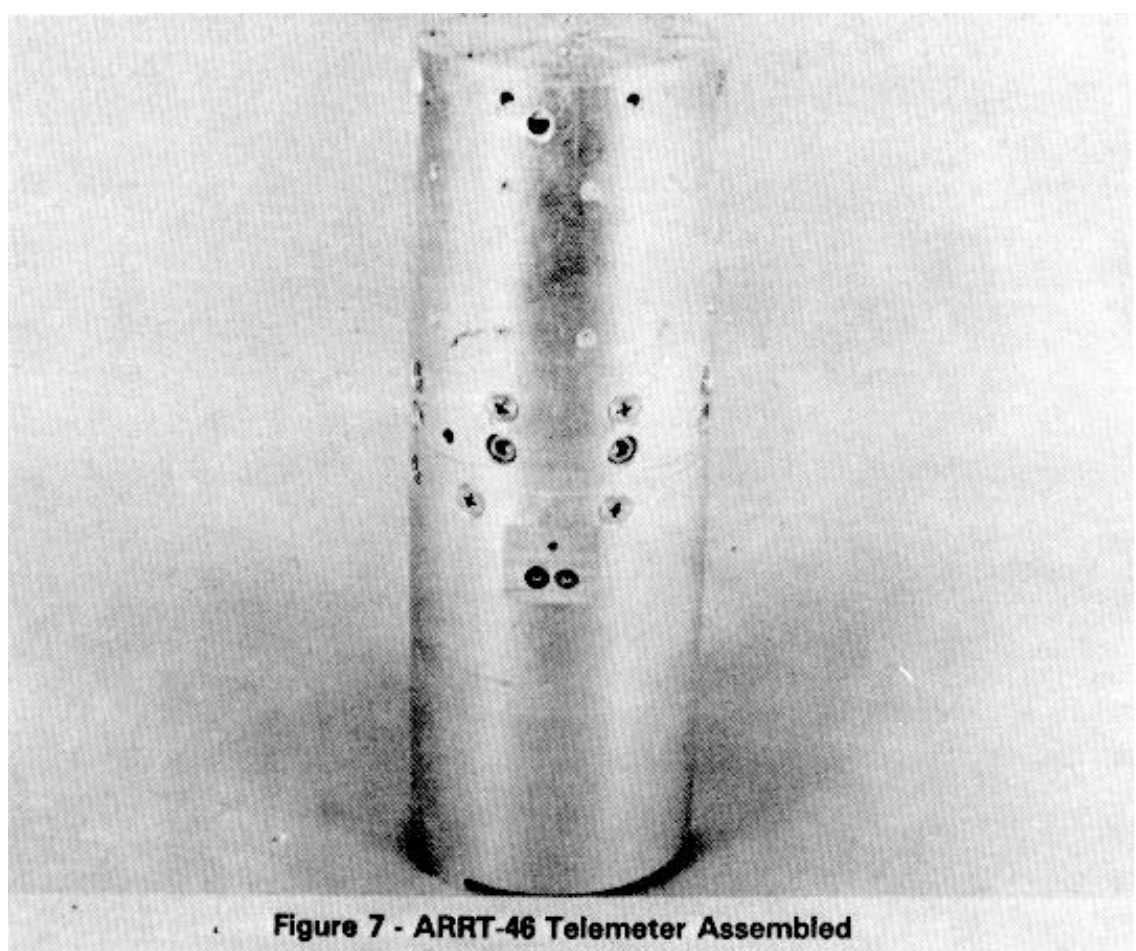




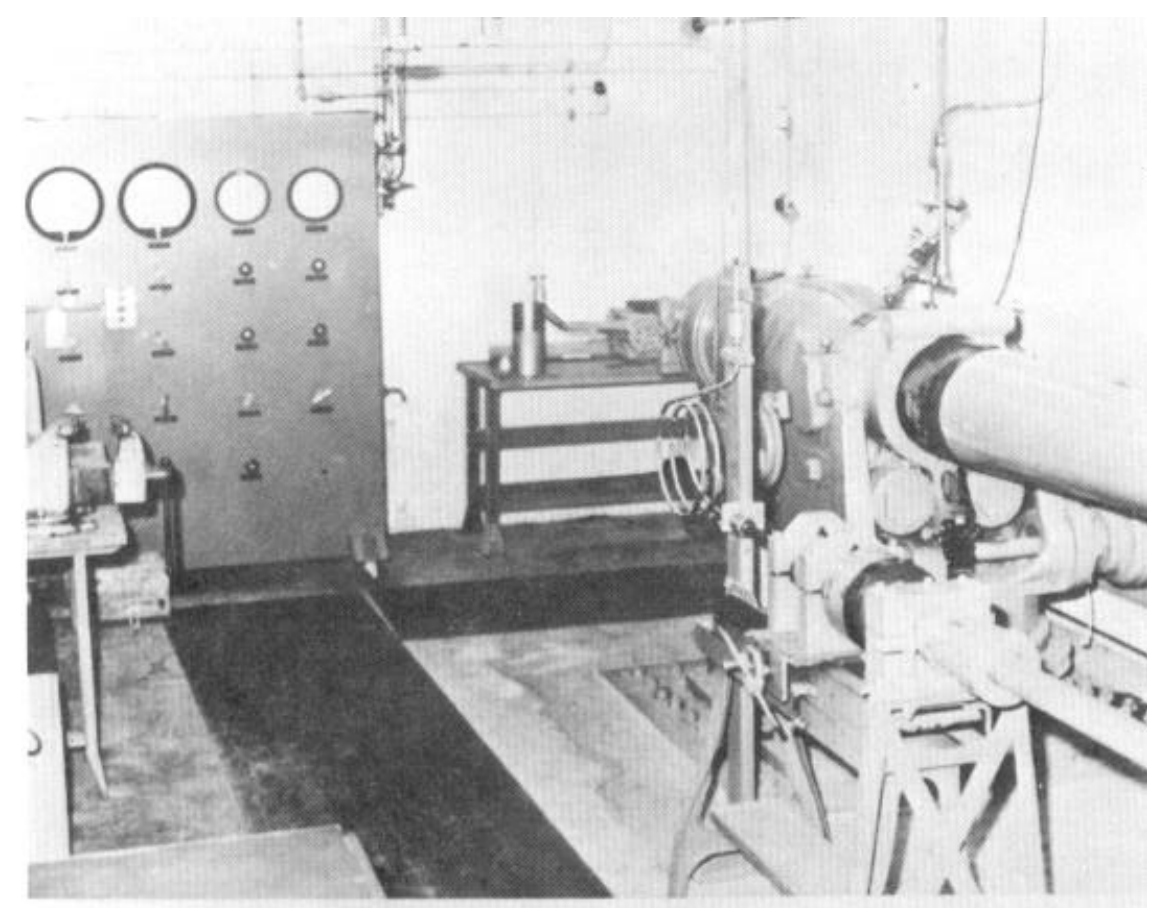

Figure 8 - 2" and 5" Air Guns-Breech End

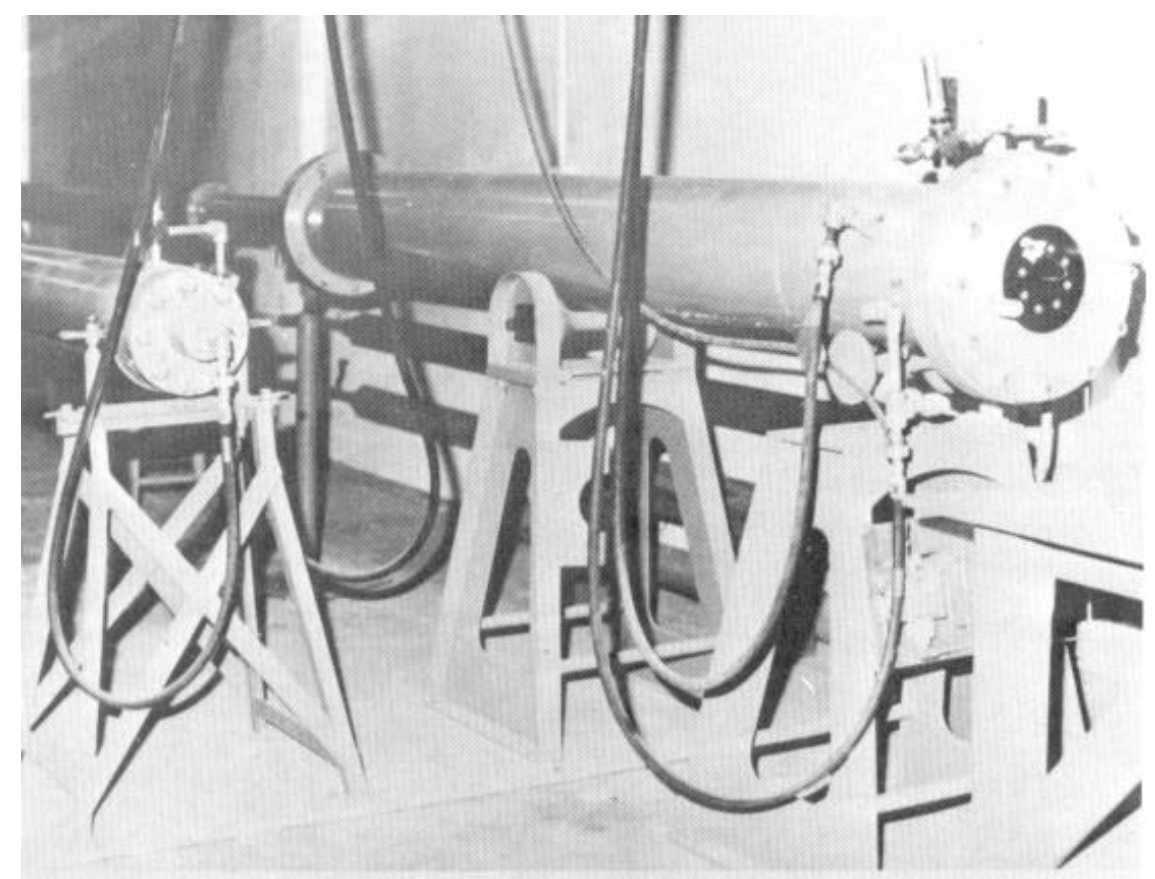

Figure 9 - 2" and 5" Air Guns-Capture End 


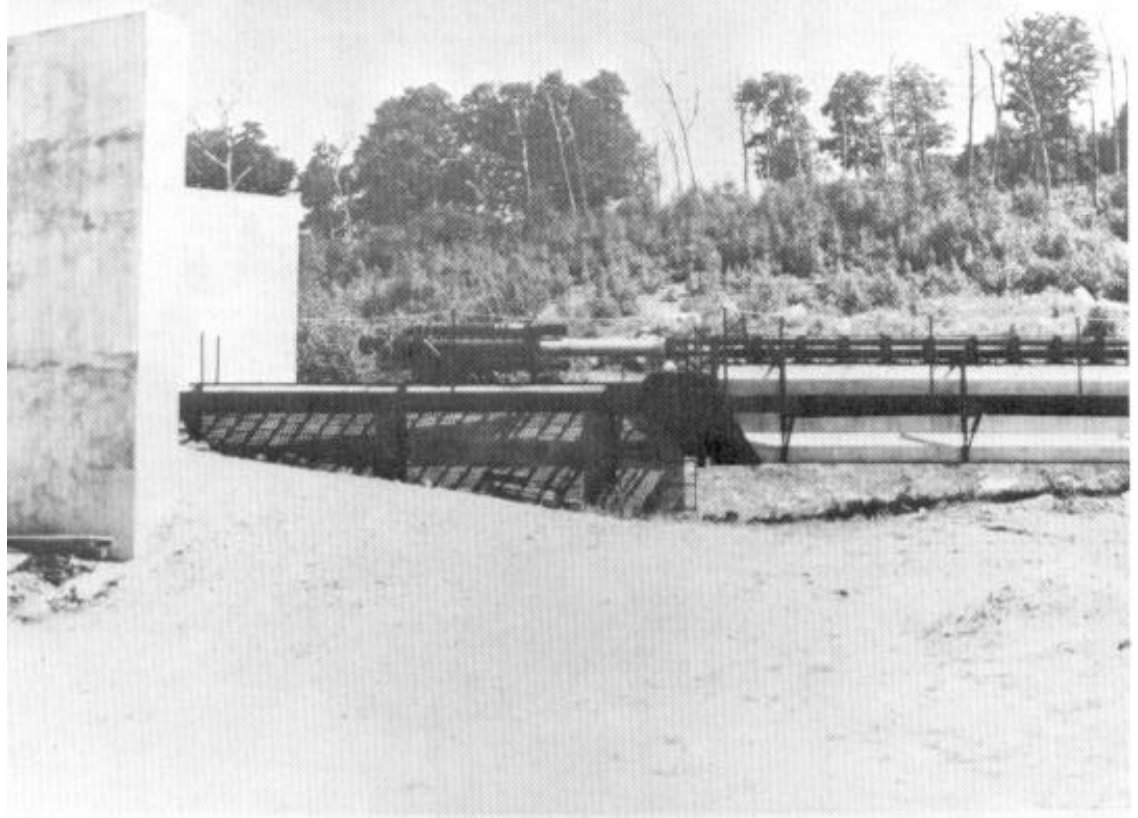

Fiqure 10 - Arradcom Ballistic Rail Gun Facility (Side View)

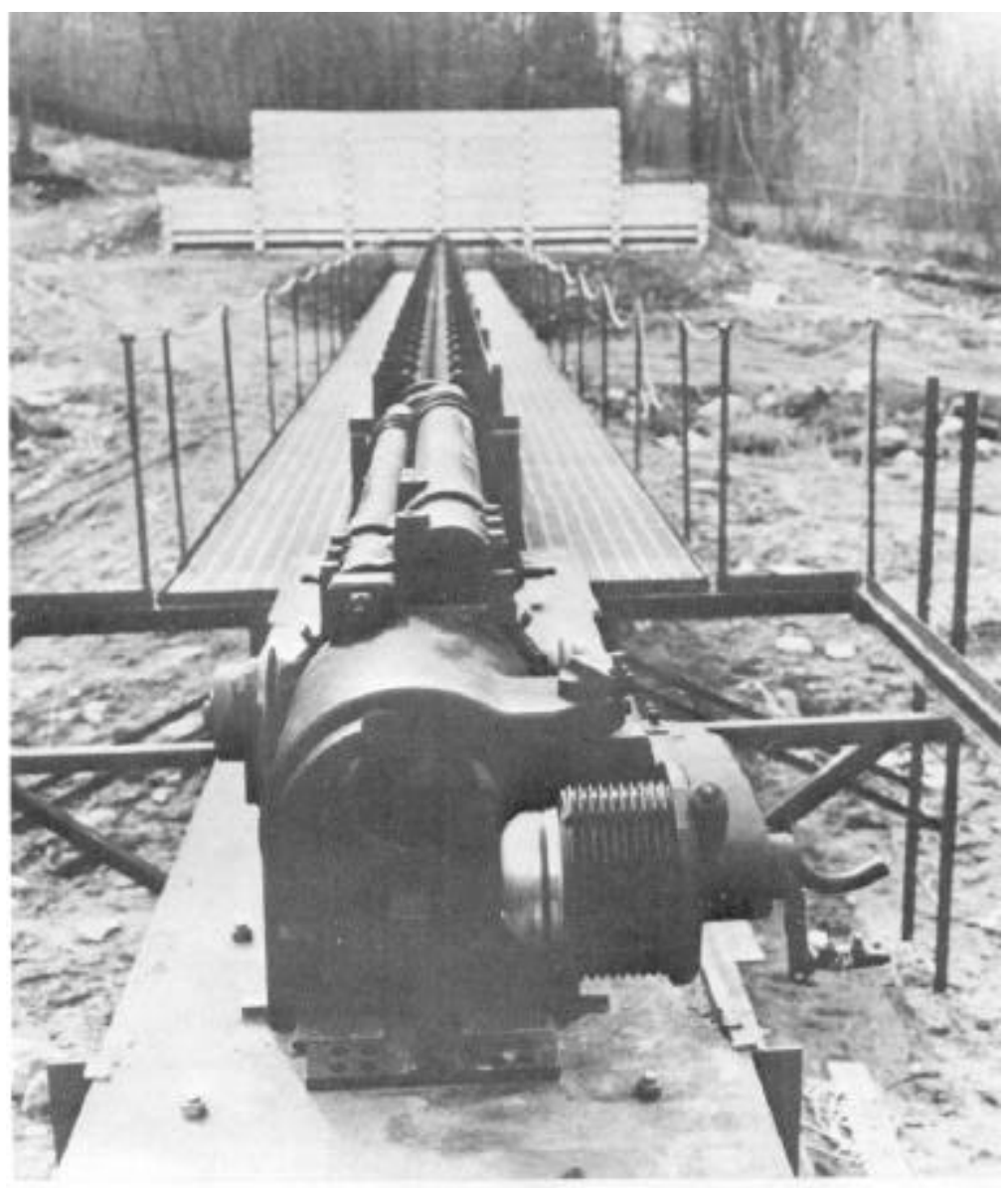

Figure 11 - Arradcom Ballistic Rail Gun Facility (Longitudinal View) 


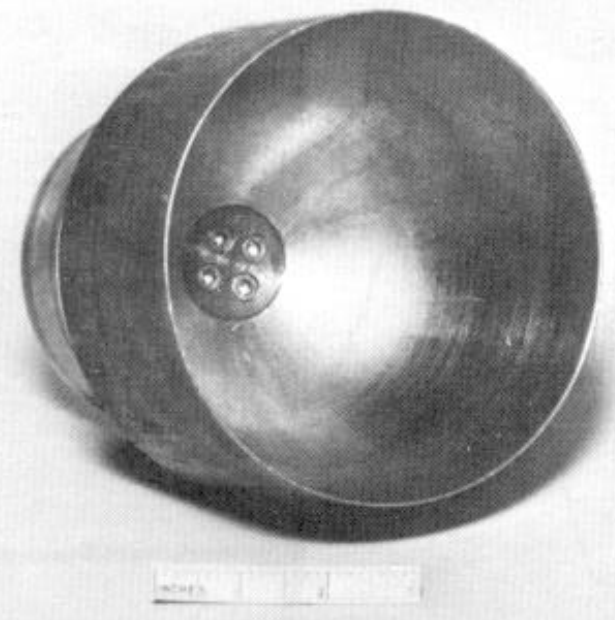

Figure 12 - Rail Gun Projectile Water Scoop

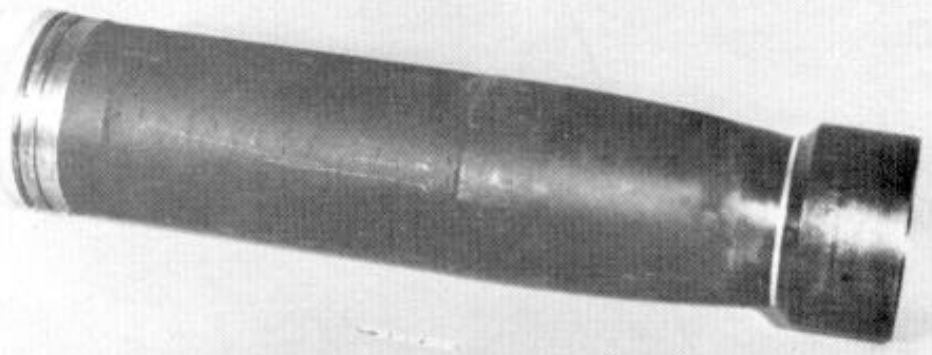

Figure 13 - Assembled Rail Gun Projectile 


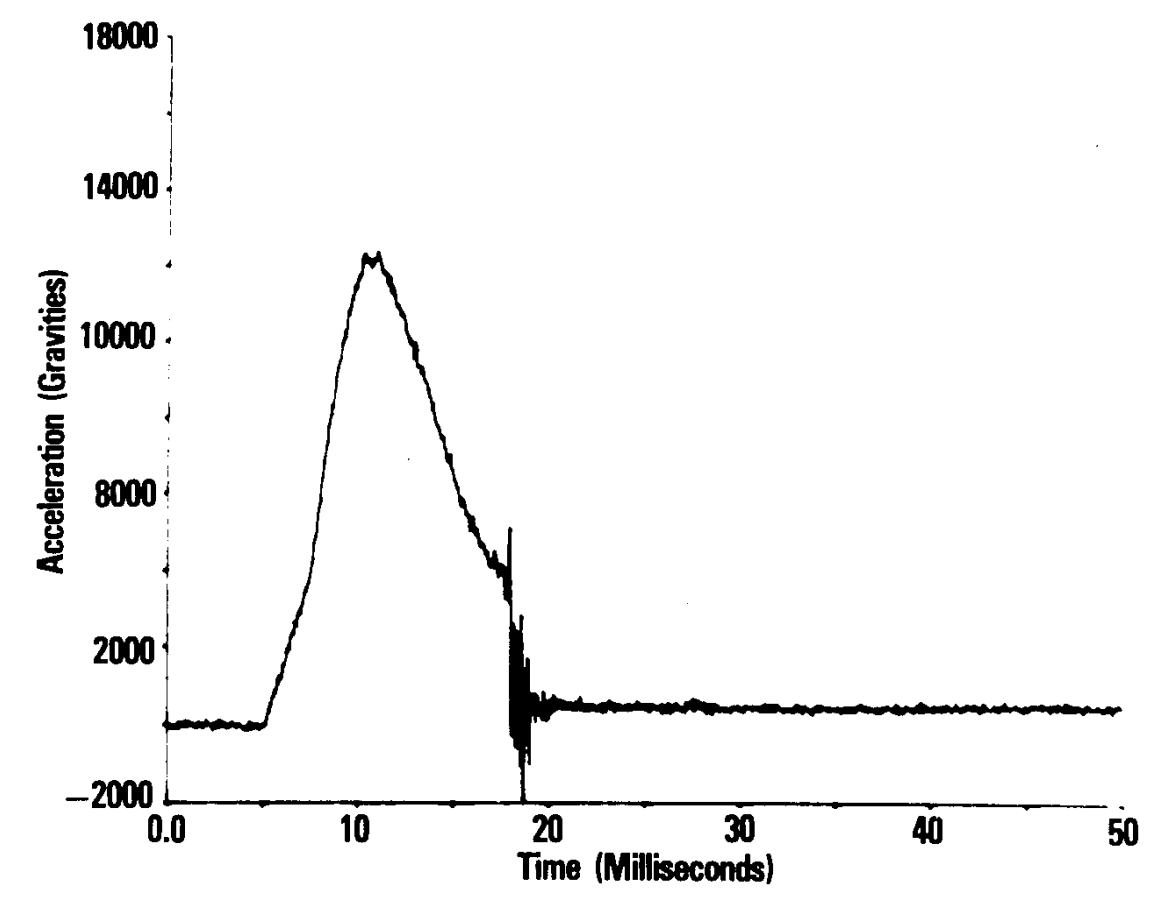

Figure 14 - XM785 In-bore Telemetry Test, Axial Acceleration vs Time

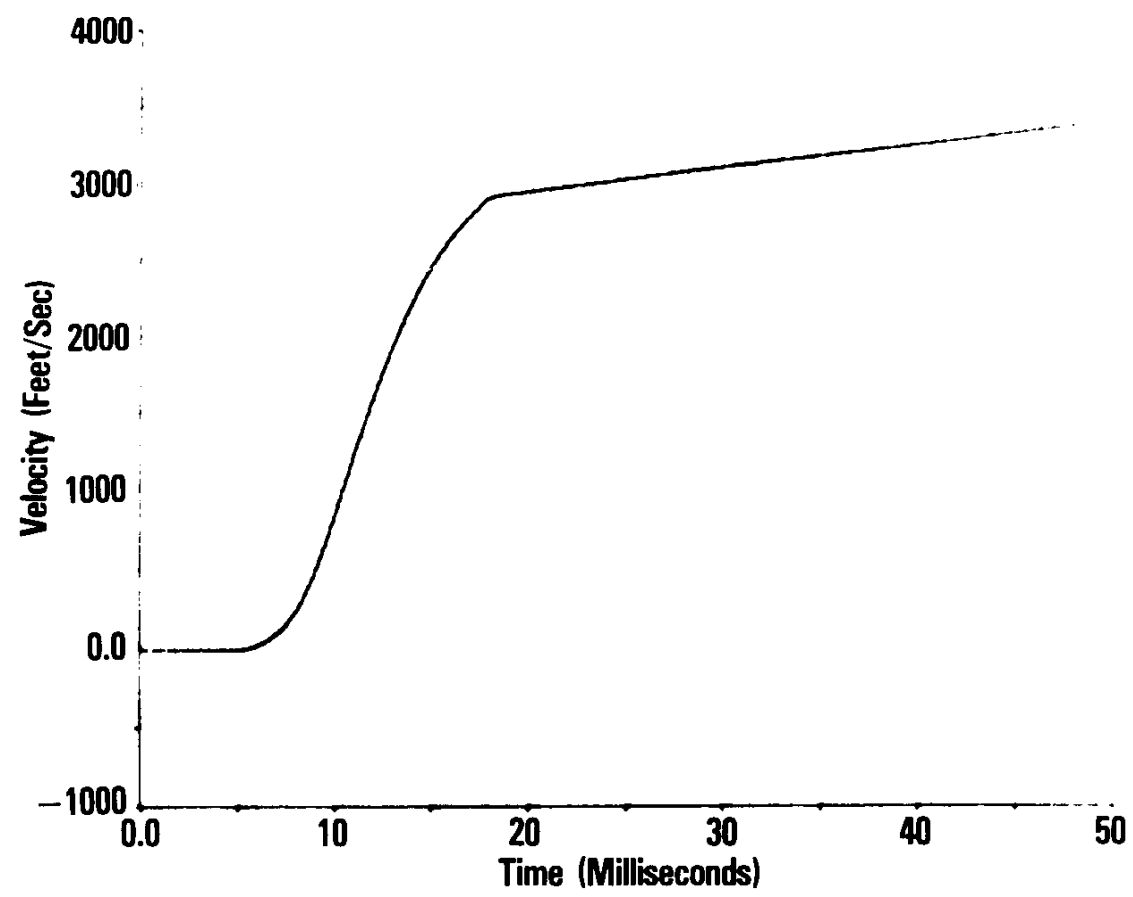

Figure 15 - XM785 In-bore Telemetry Test, Axial Velocity vs Time 


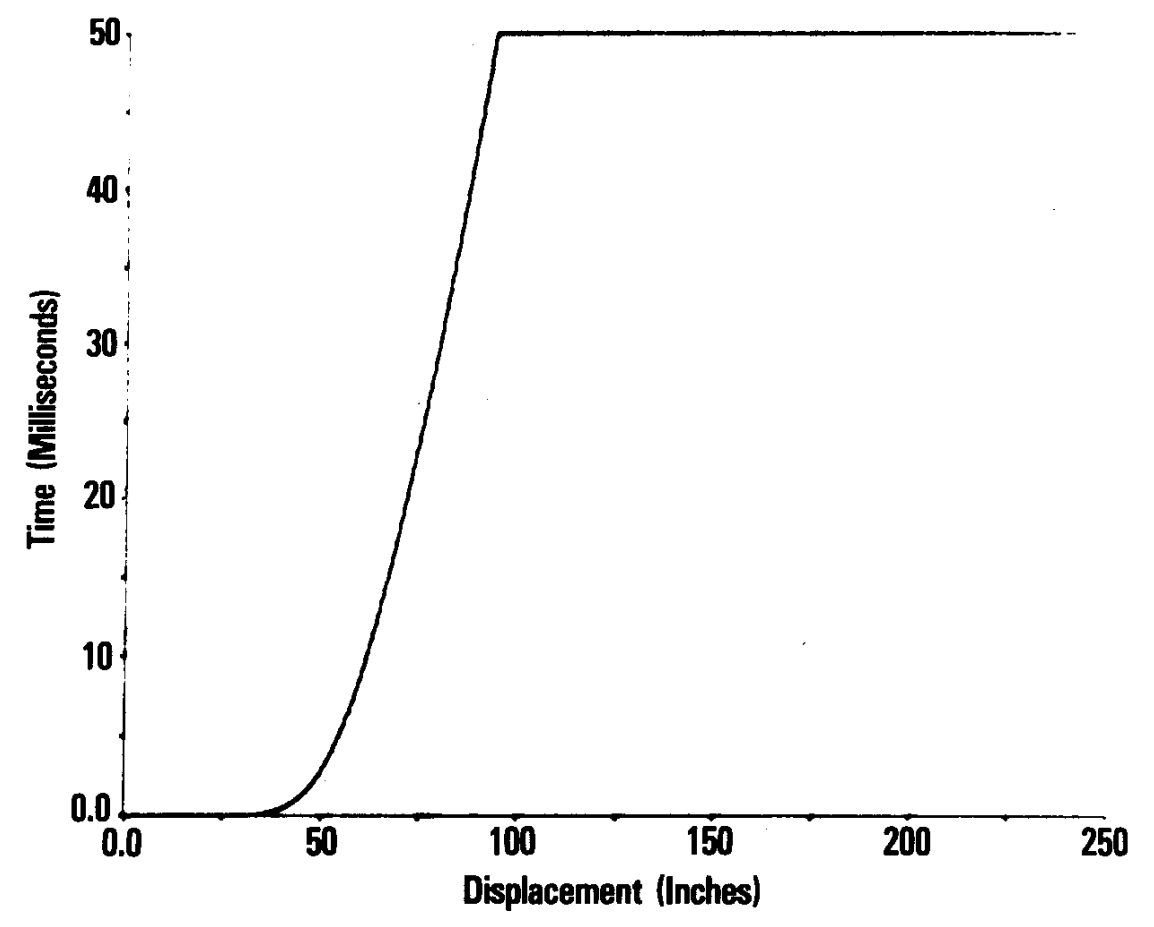

Figure 16 - XM785 In-bore Telemetry Test, Axial Displacement vs Time

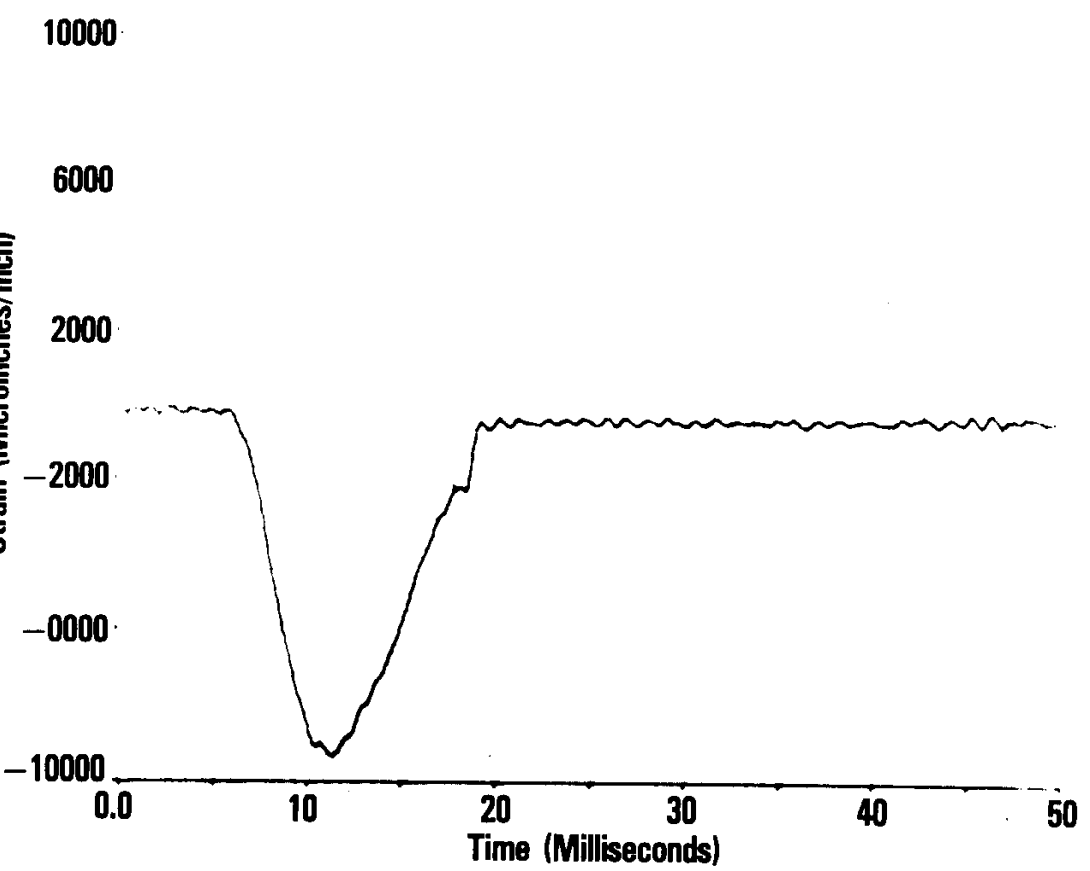

Figure 17 - XM785 In-bore Telemetry Test, Strain Gage 


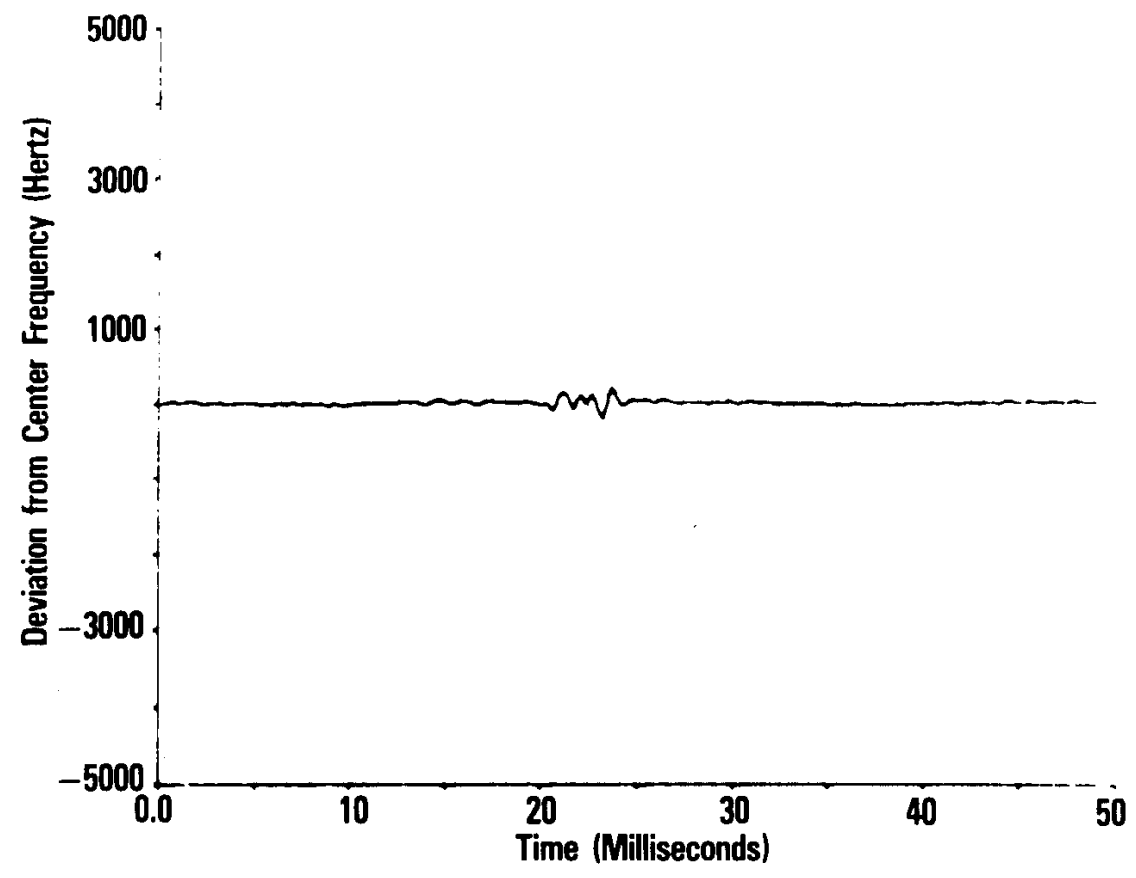

Figure 18 - XM785 In-bore Telemetry Test, Reference Channel - Center Frequency $80 \mathrm{KHZ}$ 